\title{
MÉXICO 2015: ENTRE LA FRAGMENTACIÓN PARTIDISTA Y EL DESCONTENTO CIUDADANO
}

\author{
Mexico 2015: Between Partisan Fragmentation and \\ Public Disaffection
}

\section{FLAVIA FREIDENBERG}

Instituto de Investigaciones Jurídicas, UNAM

\section{FRANCISCO JAVIER APARICIO}

Centro de Investigación y Docencia Económicas, A. C.

\begin{abstract}
RESUMEN
2015 fue un año muy complejo para México. No solo porque celebró unas elecciones críticas, que suponían la implementación de una reforma electoral constitucional compleja, sino porque se dieron en un contexto de alta conflictividad social, inseguridad y violencia política, y en el marco de un cada vez mayor descontento ciudadano respecto de la política. A tres años del inicio de su mandato, el presidente Peña Nieto experimentó un escenario económico adverso y una caída significativa en los niveles de aprobación ciudadana tras diversos sucesos como la tragedia de Ayotzinapa, denuncias por corrupción y las dificultades para satisfacer las expectativas de la ciudadanía sobre el crecimiento económico. Gracias a una fragmentación inédita del voto, la coalición gubernamental logró mantener la mayoría en el Congreso.
\end{abstract}

Palabras clave: México, elecciones intermedias, reforma 2014, violencia política, desconfianza ciudadana.

\begin{abstract}
Mexico had a complicated year in 2015. It was a critical mid-term election year, organized under new electoral rules, amidst social unrest, insecurity and political violence accompanied by an increasing social disaffection with politics. After three years in office, President Peña Nieto faced adverse economic conditions and a significant decrease in approval rates after damaging events such as the Ayotzinapa tragedy, corruption scandals and low economic growth. However, due to an unprecedented vote fragmentation, the ruling coalition was able to retain its majority in the Chamber of Deputies.
\end{abstract}

Key words: Mexico, midterm elections, electoral reform, political violence, social disaffection. 


\section{INTRODUCCIÓN*}

El año 2015 se caracterizó por la celebración de elecciones intermedias a nivel federal, un conjunto de elecciones locales críticas, la implementación de las reformas políticoelectorales de 2014, el incremento de la violencia política hacia los candidatos y la prensa, la crisis económica, el crecimiento de la pobreza y un escenario de movilización social y descontento ciudadano, debido entre otras cosas a la falta de esclarecimiento por la desaparición de los estudiantes de la Escuela Normal Rural de Ayotzinapa (septiembre de 2014), el escándalo de presunta corrupción por la "casa blanca" (noviembre de 2014) y la fuga de Joaquín Guzmán Loera, el narcotraficante conocido como el "Chapo" Guzmán (julio de 2015).

Las elecciones federales y locales de ese año fueron un gran laboratorio, con nuevas reglas de juego, nuevos incentivos, nuevo árbitro y un electorado crítico y desafiante, en un clima de creciente descontento. Las elecciones se realizaron bajo nuevas reglas, producto del "Pacto por México", negociado y aprobado por los tres principales partidos nacionales (Partido Revolucionario Institucional, Partido de la Revolución Democrática y Partido Acción Nacional) en 2013 (Barrientos del Monte y Añorve Añorve, 2014), lo que condujo a la reforma político-electoral constitucional y legal de 2014, que supuso cambios importantes, como la creación del Instituto Nacional Electoral, la introducción de las candidaturas independientes o sin partido, y la puesta en marcha de la paridad de género en las candidaturas para cargos de representación popular.

Las elecciones se realizaron en un contexto complejo, con un alto nivel de conflictividad social, inseguridad y violencia política. El clima sociopolítico estaba enrarecido y, por momentos, parecía "de calma chicha". El contexto social en el que se desarrolló la elección carece de condiciones de equidad social. Cerca de 54 millones de ciudadanos mexicanos se encuentra en la pobreza, lo que dificulta el acceso a los recursos, dando mayores oportunidades para el desarrollo de malas prácticas, instituciones informales y comportamientos de los actores políticos, alejados de las reglas aprobadas en el marco legal del sistema político.

El artículo inicia con la descripción de los sucesos más significativos en términos políticos, sociales y económicos en 2015. Luego se analizan los principales cambios institucionales realizados a partir de la reforma político-electoral de 2014, mismos que fueron implementados en las elecciones intermedias de junio de 2015. El trabajo continúa con el análisis de los resultados electorales, el comportamiento de los actores clave y la nueva configuración del gobierno. Finalmente, se realiza una evaluación general del funcionamiento de la democracia mexicana.

* Agradecemos a un evaluador externo de la Revista de Ciencia Política, quien con sus sugerencias y comentarios críticos han enriquecido este trabajo. 


\section{TEMAS RELEVANTES EN 2015}

\section{Coyuntura política y social}

Si 2013 puede considerarse como un año de intensa actividad legislativa para avanzar una ambiciosa agenda de reformas estructurales, 2014 fue un año mucho más sombrío, cifrado entre la tragedia y el escándalo. Entre finales de 2014 y mediados de 2015 la coyuntura mexicana estuvo marcada por tres hechos fundamentales en términos políticos y sociales. Primero, por la trágica desaparición en Iguala en Guerrero de 43 estudiantes normalistas de la escuela rural de Ayotzinapa, asunto que impactó de manera importante a la opinión pública nacional e internacional y que ha generado movilizaciones de la ciudadanía reclamando verdad y justicia en relación con lo sucedido.

Poco después, en noviembre de 2014, surgió el escándalo de la "casa blanca", un incidente de presunta corrupción que involucraba al Presidente y su secretario de Hacienda, entre otros, con un importante contratista gubernamental. Posteriormente, en julio de 2015 y ya pasadas la elecciones, ocurrió la fuga del famoso narcotraficante Joaquín Guzmán Loera, mejor conocido como el "Chapo", de una de las prisiones de más alta seguridad del país, poniendo de manifiesto las dificultades que tiene el Estado mexicano para cumplir varias de sus funciones básicas.

El caso de Ayotzinapa devolvió los reflectores al tema de la violencia y la inseguridad que los voceros gubernamentales quisieron minimizar durante los dos años previos. Si bien las tasas de homicidios y robos con violencia fueron menores en 2015 que en 2013, la percepción de inseguridad no disminuyó. Por otra parte, la violencia contra la prensa aumentó 21,8\% al pasar de 330 agresiones en 2014 a 397. En los tres primeros años de Enrique Peña Nieto se han documentado 1.073 agresiones, 19 asesinatos y tres reporteros desaparecidos. ${ }^{1}$ La violencia ha llegado, inclusive, hasta élites políticas y tan solo entre 2013 y 2014 hubo 130 víctimas letales entre autoridades y candidatos locales (Trejo y Ley, 2015).

\section{Coyuntura económica}

Un factor externo clave para entender cómo cambió el entorno económico -y, por consiguiente, las finanzas públicas del gobierno mexicano durante 2015-, es el precio internacional del petróleo. En los últimos seis meses de 2014 el precio internacional del petróleo cayó en más de 50\%, y siguió haciéndolo durante 2015. El precio del petróleo es clave para México, porque es un país exportador de crudo y, sobre todo, es un factor clave para el erario: en general, 3 de cada 10 pesos de los ingresos del gobierno federal provienen de la venta de petróleo.

\footnotetext{
“El 2015 ha sido un año increíblemente violento para la prensa", sostuvo Darío Ramírez, director en México de Artículo 19, que vela por la libertad de expresión. En 2015, Artículo 19 contabilizó 397 agresiones y 7 asesinatos de periodistas. Los estados con más violencia contra los informadores son la Ciudad de México, Guerrero y Puebla. Publicado por El País América. 2016. “El 2015 fue el año más violento para la prensa en México" (17 de marzo). En: http://internacional.elpais.com/internacional/2016/03/17/mexico/1458249778_423135.html Consulta realizada: 24 de marzo de 2015.
} 
El presupuesto de egresos de la Federación para 2015 consideraba un precio base de 79 dólares por barril. Sin embargo, durante la mayor parte del año la mezcla mexicana se vendió en alrededor de 40 dólares. A diferencia de la década de 1980, la economía mexicana ya no depende tanto de las exportaciones de petróleo y existe una economía diversificada. Sin embargo, las finanzas públicas siguen dependiendo de manera significativa de la renta petrolera.

Con la reforma energética aprobada en 2013, también en el marco del "Pacto por México", el gobierno apostaba a inducir altos niveles de inversión extranjera con la esperanza de aumentar la tasa de crecimiento económico. Con la caída en los precios del petróleo esto no ocurrió y representó malas noticias para la economía nacional y, sobre todo, para las finanzas públicas.

Cuando el crecimiento económico, los ingresos fiscales o la renta petrolera resultan menores a lo esperado, hay dos consecuencias posibles: o aumenta el déficit presupuestal y el endeudamiento, o bien hay un recorte presupuestal. Los niveles de gasto y déficit que parecían tolerables en 2013, ya no lo fueron durante 2015, ni lo serán en el mediano plazo. Como indica la Tabla 1, las tasas de crecimiento económico han sido inferiores a las anunciadas por el gobierno federal al inicio del sexenio. Entre 2013 y 2015 el PIB de México creció 1,1, 2,6 y 2,5\% respecto del año anterior, es decir, tasas inferiores al $3,5 \%$ observado en 2012. Ante esta circunstancia y el deterioro en los ingresos públicos, el gobierno se vio obligado a hacer un recorte presupuestal en 2015 y a presentar un presupuesto de egresos más bien modesto para 2016. En noviembre de 2015 el presupuesto de egresos para 2016 fue aprobado con 441 votos a favor (90\% de un quórum de 487 legisladores en la Cámara) y solo 38 votos en contra. ${ }^{2}$

Si bien el PIB per cápita en dólares aumentó entre 2012 y 2014, la depreciación del tipo de cambio observada desde finales de 2015 ha impactado el poder adquisitivo de los mexicanos. Por su parte, tanto los niveles de pobreza como los de desigualdad en la distribución del ingreso se han mantenido en niveles muy similares a los observados al inicio del sexenio. Desde un punto de vista de mediano y largo plazo, la alternancia política observada en 2000 y 2012 no ha estado acompañada de una mejoría en el ritmo de crecimiento económico del país, ni en la disminución de la pobreza y desigualdad, lo que puede pensarse como elementos asociados al deterioro de los niveles de confianza ciudadana existentes en el país. ${ }^{3}$ 
Tabla 1. Evolución de los principales indicadores económicos de México

\begin{tabular}{lcc}
\hline Indicador & 2012 & 2015 \\
\hline Tasa de crecimiento PIB & $3,5 \%$ & $2,5 \%$ \\
Tasa de inflación anual & 3,57 & 2,13 \\
Tasa de desocupación & 4,5 & 3,9 \\
Tasa de pobreza & 45,5 & $46,2(2014)$ \\
Coeficiente de Gini & 0,440 & $0,438(2014)$ \\
PIB per cápita (dólares US) & $\$ 9.703,40$ & $\$ 10.325,60(2014)$ \\
\hline
\end{tabular}

Fuentes: INEGI, Banco de México, Coneval, ENIGH (INEGI), Banco Mundial.

\section{NUEVAS ELECCIONES, NUEVAS REGLAS}

La reforma político-electoral a nivel constitucional aprobada en 2013, y que entró en vigor el 10 de febrero de 2014, introdujo tres temas importantes: permitir la reelección de legisladores y alcaldes (misma que estuvo prohibida por más de ochenta años), obligar a los partidos políticos a registrar candidaturas legislativas con paridad de género y un nuevo esquema de gobernanza electoral. ${ }^{4}$

El nuevo "sistema nacional electoral" transformó los 32 institutos locales y el federal para crear un solo instituto que nacionalizara el proceso de toma de decisiones, la fiscalización de los recursos públicos otorgado a los partidos así como sus campañas electorales y la rendición de cuentas. Con esta reforma se dotó al nuevo Instituto Nacional Electoral (INE), antiguo Instituto Federal Electoral, de 74 nuevas competencias que ha tenido que implementar de manera muy rápida para organizar las elecciones de junio y julio de 2015, al mismo tiempo que se designaban a los nuevos consejeros y consejeras de los organismos estatales que tendrían elecciones concurrentes ese mismo año. ${ }^{5}$

Las actividades electorales de este nuevo INE agigantado supuso desafíos importantes en la gestión de las elecciones de 2015. Es más, incluso se llegó a entender que los Consejeros debieron "aprender a organizar nuevamente las elecciones mientras estaban en proceso electoral". ${ }^{6}$ La nueva integración de los organismos públicos locales (OPLEs), la definición

4 La reforma constitucional fue publicada en el Diario Oficial de la Federación el 10 de febrero de 2014. La reforma legal fue publicada el 23 de mayo de 2014.

5 Las reformas caminaron hacia un nuevo modelo de gestión electoral, centrado en nuevas atribuciones y facultades para el Instituto Nacional Electoral, la supresión de atribuciones a los institutos estatales electorales y la construcción de un nuevo esquema de relación entre el nuevo instituto nacional y sus entidades estatales, lo que supuso desafíos importantes no solo a la burocracia electoral sino también a las autoridades electorales estatales y federales. De ahí, las facultades de asunción, atracción y delegación que se le da al INE para organizar y vigilar las elecciones locales -siempre y cuando se actualicen ciertos supuestos de ley-así como también el nuevo procedimiento especial sancionador que será resuelto por el Tribunal Electoral del Poder Judicial de la Federación mediante una sala especializada.

6 Declaraciones del Consejero Presidente del INE, Lorenzo Córdova Vianello, en el Foro para Visitantes Extranjeros, en la Ciudad de México del 4 al 6 de junio de 2015. 
de los contenidos de los convenios de colaboración respecto de cuáles eran las tareas de las nuevas unidades operativas y la redistribución de las tareas entre el INE y estas nuevas instancias locales, elegidas por la organización nacional pero dependientes en materia de recursos y presupuesto de la entidad federativa, han supuesto retos importantes para sostener un comportamiento equilibrado entre los actores participantes.

Estas reformas han generado un nuevo andamiaje institucional y han supuesto un nuevo modelo de gobernanza de las elecciones, abandonando, en parte, el esquema previo de federalismo electoral que establecía que cada Estado de la Federación se daba sus reglas electorales. La reforma buscó dar respuesta a varias interrogantes que tienen que ver con cómo construir una elección con equidad en la competencia; cómo garantizar unos mínimos de igualdad en el acceso a los medios de comunicación masivos, cómo conseguir estándares mínimos para poder fiscalizar el uso de los recursos públicos o cómo garantizar el acceso igualitario y paritario a las candidaturas a los cargos de representación popular.

El INE pasó también a responsabilizarse de la fiscalización en línea de los recursos que se le otorgan a los partidos políticos nacionales y locales, situación que en el ámbito estatal era facultad de las autoridades locales; la demarcación de los distritos electorales, que a nivel local era facultad de los institutos electorales de cada entidad; la instalación de "casillas electorales únicas", ya que en procesos electorales concurrentes se instalaban casillas diferenciadas para recibir la votación tanto de las elecciones federales como locales y tras la reforma se procedió a la instalación de una casilla para todos los procesos, con el objeto de racionalizar y agilizar la emisión del voto por parte de la ciudadanía.

Las reformas introdujeron además las candidaturas sin partidos (denominadas en la ley como candidaturas independientes). Desde 2014 convive un sistema de postulación "mixto", que hace convivir la presentación de candidaturas por partidos junto al ejercicio del derecho a la libre postulación para los diferentes cargos (Astudillo Reyes, 2016). ${ }^{7}$ Las reglas autorizaron la presentación de candidaturas de libre postulación para Presidente de la República, diputados federales y senadores por el principio de mayoría relativa. ${ }^{8}$ Los aspirantes deben pasar un complejo sistema de preselección, previo registro de su intención de competir en el Instituto Nacional Electoral, seguido de un plazo en el que deben conseguir apoyo ciudadano en función del tipo de cargo en el que quieren competir. ${ }^{9}$

7 Hasta ese momento, "no había una norma expresa que las prohibiera, pero sí algunas normas que las hacían imposibles". Ver María Marván Laborde. 2015. “Ciudadanos y políticos: la falsa distinción”. Entrevista de Emiliano Balerini Casal, Este País 291 (julio): 5-8.

$8 \quad$ Diario Oficial de la Federación, publicado el 23 de mayo de 2014.

9 Para postular como candidato independiente al cargo de Presidente de la República se deberá obtener el apoyo de al menos el equivalente al $1 \%$ de la lista nominal de electores en el plazo de 120 días, integrada por electores a lo menos de diecisiete entidades federativas (unas 814.277 firmas); para el cargo de senador por mayoría relativa, el aspirante deberá conseguir el $2 \%$ de la lista nominal de electores correspondiente a la entidad federativa a representar en un porcentaje de por lo menos la mitad de los distritos electorales en un plazo de 90 días y para diputado federal deberá obtener el apoyo de al menos el $2 \%$ de la lista nominal de electores correspondiente al distrito electoral a representar, en un porcentaje de al menos la mitad de las secciones electorales en el plazo de 60 días (ver LGIPE, 2014). 
La reforma también introdujo la obligación de registrar fórmulas de candidatos con paridad de género. Eso supuso la inclusión de la exigencia de paridad en el acceso a los cargos de representación popular: los partidos deben presentar el 50\% de las candidaturas con hombres y el otro $50 \%$ con mujeres a la Cámara de Diputados y al Senado, tanto por el principio de mayoría relativa como el de representación proporcional, con candidaturas suplentes del mismo género, y eliminando cualquier excepción al principio de paridad por el uso de algún método competitivo de selección de candidaturas y prohibiendo que se destinaran a las candidatas mujeres a distritos perdedores (o no competitivos). ${ }^{10}$

\section{RESULTADOS ELECTORALES EN 2015}

Las elecciones federales y locales del 7 de junio de 2015 tuvieron un especial relieve desde tres ángulos distintos: la reñida composición del Congreso, la implementación de la nueva reforma electoral y las crecientes señales de descontento social que se pusieron de manifiesto por parte de la ciudadanía. Estas elecciones pasarán a la historia como un proceso más en la democratización mexicana. En este largo y sinuoso camino, estas elecciones implicaron la renovación de 500 diputados federales y estatales, 9 gobernadores, 993 alcaldías, 16 delegados políticos en el DF y 640 diputaciones locales.

El resultado más importante de la elección federal tuvo que ver con resolver la duda si la coalición gubernamental entre el PRI, Partido Verde y Nueva Alianza mantendría la mayoría del Congreso o no. En el Congreso elegido en 2012 esa coalición contaba con 251 escaños de 500 posibles, por lo que bastaba con que la coalición perdiera al menos dos curules para cambiar el balance de poder en el Congreso, habida cuenta de que en el Senado la oposición tiene una apretada mayoría también desde 2012.

Las elecciones intermedias previas habían sido costosas para el partido en el gobierno: en 1997, año en que observamos el primer gobierno sin mayoría en México, el PRI de Ernesto Zedillo perdió 61 curules. En 2003 la bancada del PAN de Vicente Fox perdió 54 curules y Felipe Calderón perdió 63 escaños en 2009. Tanto en 2003 como en 2009 el PRI había capitalizado el desgaste del PAN sin necesidad de hacer un gran esfuerzo ni campañas negativas. ¿Le tocaría a Enrique Peña Nieto perder fuerza en el Congreso al igual que sus tres antecesores?

En segundo lugar, las elecciones fueron un estupendo laboratorio para evaluar en qué medida la reforma constitucional de 2014, que incluía la introducción de la paridad en las candidaturas legislativas y la posibilidad de que se presentaran candidaturas independientes de los partidos, contribuía a romper el escenario de exclusión que se denunciaba que existía en el sistema político mexicano. En tercer lugar, el proceso

10 La nueva Ley General de Partidos sostiene que “cada partido determinará y hará públicos los criterios para garantizar la paridad de géneros en las candidaturas a legisladores federales y locales. Estos deberán ser objetivos y asegurar condiciones de igualdad entre los géneros" (Artículo 3, LGP 2014). 
electoral supuso también altos niveles de incertidumbre en las semanas previas a la elección, algo inédito para una elección intermedia, debido al comportamiento de ciertos actores sociales que amenazaron incluso con boicotear el proceso en Guerrero y Oaxaca, así como también de la propia ciudadanía, que comenzó a manifestar síntomas de cansancio y desencanto con la política.

Esta ha sido una elección clave en términos del tamaño del padrón electoral, en el costo de la contienda y en los desafíos generados por los cambios en las reglas de juego, que exigieron nuevas habilidades y nuevas prácticas por parte de los actores participantes, ya sean los partidos políticos, los candidatos sin partidos, la autoridad electoral, los medios de comunicación de masas e incluso los electores, que debieron participar como funcionarios de casilla o como electores.

El padrón electoral de esta elección ha sido uno de los más grandes de América Latina. 83,5 millones de ciudadanos fueron llamados a participar y votar; 1.210.086 ciudadanos capacitados para hacerse cargo de las casillas y cerca de 47 puntos porcentuales del electorado (40 millones de personas) ejerció el derecho al voto, un porcentaje relativamente mayor a lo que había sido la participación ciudadana en las elecciones intermedias de $2003(41,8)$ o las de $2009(44,6)$, lo que incluso llegó a sorprender a muchos que esperaban una participación mucho menor.

A pesar de estos niveles de participación, el período de campaña electoral dio cuenta de la presencia de un electorado desencantado y crítico, agotado del enfrentamiento entre las dirigencias y de la vieja manera de hacer política, con sectores de la sociedad civil muy activos llamando, al igual que en 2009, al "voto nulo". Aunque el debate en torno al denominado "movimiento anulista" tuvo amplia cobertura en algunos espacios, este no se llegó a manifestar claramente en el resultado electoral: el voto nulo fue 4,76\%, un nivel más bajo que el de las elecciones intermedias de 2009.

El contexto de violencia mencionado antes también ha tenido impacto en la organización de las elecciones en México. Por un lado, en las localidades con mayores índices de violencia e inseguridad es más difícil reclutar ciudadanos como funcionarios de casilla o para que faciliten sus domicilios para instalarlas (Cantú y Ley, 2016). Por otro lado, las zonas con mayor asedio de violencia tienden a deprimir la participación electoral (Trelles y Carreras, 2012; Ley, 2014), debido a la percepción de inseguridad que se experimenta en dichos distritos.

\section{Fragmentación del voto}

Las elecciones trajeron varios resultados inesperados. A nivel federal, la primera sorpresa fue que la coalición del PRI, PVEM y PANAL retuvo la mayoría de la Cámara de Diputados. Esto fue sorpresivo, porque en general las casas encuestadoras no apostaban por ello. Como se dijo antes, en las tres elecciones intermedias previas en México el partido en el gobierno se había visto debilitado, tal como ocurre en muchos otros regímenes presidencialistas. Entre 2012 y 2015 el PRI pasó de 31,9 a 30,3\% del voto nacional. El 
PVEM, con todo y una agresiva campaña mediática, solo pasó de 6,1 a 7,3\%. Al final de cuentas, los votos del PRI y Verde sumaron 37,7\%, apenas unas décimas menos que el 38\% obtenido en 2012.

A pesar de tener prácticamente los mismos votos, la coalición entre el PRI, PVEM y Nueva Alianza obtuvo 10 curules más que antes y mantendrá su mayoría. Este resultado se puede explicar gracias a que el gobierno enfrentó a una oposición debilitada y fragmentada, incluso de una manera que hacía décadas que no se presentaba, lo que fue sorpresivo para muchos. El PAN, que obtuvo el tercer lugar en 2012, perdió aún más votos. En 2012 el PAN tuvo 25,9\% de los votos para diputados federales y en 2015 apenas alcanzó 21,8\%. Los panistas continúan siendo la segunda fuerza en el Congreso, pero lo cierto es que perdieron 4 puntos porcentuales de votos respecto de 2012. Esto sugiere que el PAN no logró capitalizar el desgaste del gobierno federal, al menos el que se dio en los últimos meses.

Se anticipaba que el PRD perdería votos frente al Movimiento de Renovación Nacional (MORENA), el nuevo partido creado por el dirigente de izquierdas, Andrés Manuel López Obrador. Realmente pocos imaginaban que MORENA conseguiría 9\% del voto nacional y que el PRD se desplomaría hasta 11,5\%. Así las cosas, entre el PAN y PRD perdieron 4 y 7 por ciento de las preferencias, mientras que Morena consiguió $9 \%$. Por su parte, Movimiento Ciudadano, un partido también de reciente creación, pasó del 4\% en 2012 a $6,9 \%$ de votos.

Gráfico 1. Elecciones Cámara de Diputados México, 2012-2015

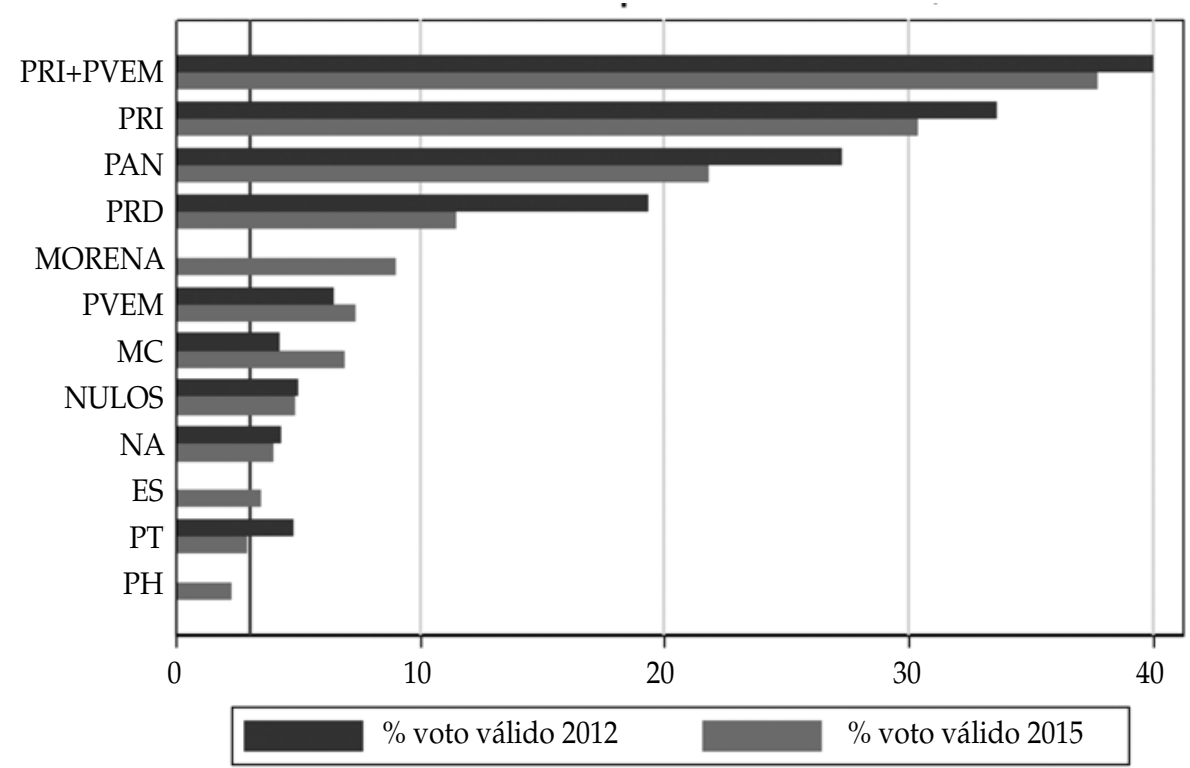

Fuente: Elaborado a base de cómputos distritales IFE 2012 vs. cómputos INE 2015. 
Gráfico 2. Cambio en porcentaje de votos por partido 2015 vs. 2012. Elecciones para Cámara de Diputados

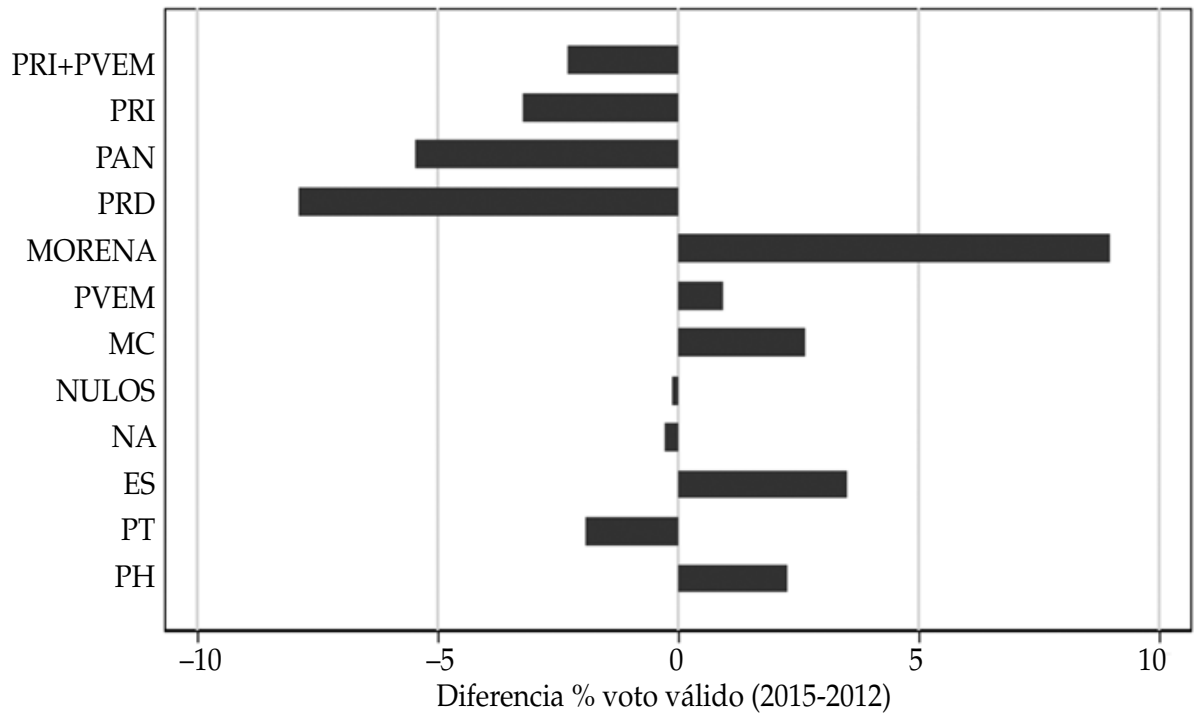

Fuente: Elaborado a base de cómputos distritales IFE 2012 vs. cómputos INE 2015.

En resumen, los tres partidos que tradicionalmente concentraban la gran mayoría de los votos en el Legislativo mexicano perdieron fuerza en 2015 (Gráfico 2). Y todos los partidos pequeños aumentaron o mantuvieron su fuerza, con excepción del Partido del Trabajo (PT). En el corto plazo, la fragmentación del voto ayudó al partido en el gobierno. Sin embargo, en el largo plazo la coalición gobernante puede ser vulnerable ante una coalición opositora, ya sea de izquierda o derecha.

La fragmentación del voto observada en 2015 es mucho más clara si se analiza el panorama de las elecciones locales que se celebraron de manera concurrente. Cinco de las nueve entidades con gubernaturas en juego tuvieron alternancia: Guerrero, Michoacán, Nuevo León, Querétaro y Sonora. Solo 5 de los 16 congresos estatales renovados obtuvieron mayoría priísta. Esto es un buen síntoma para la competencia democrática, ya que la alternancia es una consecuencia de altos niveles de competitividad. En el Distrito Federal, además, se generó un cambio importante en la configuración de fuerzas en la Asamblea Legislativa, luego de décadas de comportarse como un partido hegemónico y se dio la emergencia de la nueva fuerza de izquierda, MORENA, bajo del liderazgo de López Obrador.

Al fragmentarse el voto de izquierda en la capital del país, el PRD perdería el control de la Asamblea y la mayoría de las delegaciones de la Ciudad de México. Por su parte, un candidato emergente abanderado por el partido Movimiento Ciudadano derrotaría al PRI y al PAN en Guadalajara, una importante ciudad del país. Pero sin duda la sorpresa 
mayor fue que un candidato independiente ganara por amplio margen la gubernatura de Nuevo León, un industrial estado fronterizo con Estados Unidos.

El éxito electoral de varios candidatos independientes - un gobernador, un diputado federal, un diputado local y un par de alcaldes- en las elecciones de 2015 ha alertado a los líderes de los partidos políticos tradicionales. Algunos líderes perciben a las candidaturas independientes o sin partido como una amenaza real a dos de sus cotos de poder tradicionales: el control del acceso a la boleta electoral y el control del financiamiento público para gastos de campaña. A partir de esta reforma, cualquier ciudadano que sea capaz de recabar suficientes apoyos ciudadanos (mediante un número determinado de firmas) podría llegar a la boleta electoral, independientemente de si cuenta o no con experiencia partidista o política previa. Esta figura ha llevado incluso a que las élites subnacionales reaccionaran frente al éxito de estas candidaturas porque ven amenazado su poder local, lo que les ha llevado a impulsar reformas electorales que suponen limitantes a los independientes en sus estados. ${ }^{11}$

Si bien la coalición del PRI no perdió la mayoría en la Cámara, es un hecho que hubo alternancia en 102 de 300 distritos federales uninominales. Es decir, que la distribución de curules de mayoría relativa también refleja cambios importantes, exagerados por el sesgo mayoritario de este tipo de distritos y atemperados por la asignación de curules plurinominales. Así, entre PRI, PVEM y la Nueva Alianza pasaron de controlar 251 a 261 curules. Por su parte, la bancada del PAN decreció de 114 a 109 escaños. La bancada del PRD pasó de 100 a 60 curules, mientras que la de Movimiento Ciudadano aumentó de 20 a 25 y Morena inició con 36.

¿Cómo fue posible que, perdiendo votos, el PRI y sus aliados mantuvieran la mayoría en la Cámara? La razón de esta incógnita está en el hecho de que sus principales opositores perdieron muchos más votos aún. Por un lado, la fractura del PRD ante Morena era obvia y quizá hasta saludable -porque daba una dosis de pluralismo al Distrito Federal-. Por su parte, el PAN perdió importantes votos tanto en Nuevo León como en Jalisco, entidades otrora bastiones del panismo.

Esta elección también ha evidenciado la persistencia de ciertos rasgos de una cultura autoritaria, legado de un régimen político de partido hegemónico, que aún requiere una profunda regeneración democrática que ponga en evidencia, sancione y penalice el ejercicio de malas prácticas como el clientelismo, la compra de voto, el acarreo, el accionar de los "mapaches" o de los grupos de choque que días antes de las elección tanto en algunas delegaciones del Distrito Federal como en diversos estados del país, empañaron con su comportamiento el proceso electoral. El caso de Chiapas es ilustrativo. En la elección federal de 2015 el Partido Verde obtuvo 6,9\% del voto nacional, pero en Chiapas consiguió el 45,5\% y la coalición entre PRI y PVEM sumó el 69,39\% de los

11 Tras las elecciones del 7 de junio de 2015, en los estados de Veracruz, Chihuahua y Sinaloa, donde hay mayoría priísta en sus congresos locales, se aprobaron reformas que ponen límites a las candidaturas independientes. Estas entidades, encabezadas por gobernadores del Partido Revolucionario Institucional (PRI), celebran elecciones en junio de 2016. 
votos. Por otro lado, en 2015 la participación electoral en las casillas rurales del país fue mayor que en las casillas urbanas: $50 \%$ vs. $43 \%$. Pero en Chiapas, este diferencial fue de 16,7 puntos.

\section{Paridad de género}

Otra de las novedades de las elecciones de 2015 fue que, por primera vez, los partidos políticos estuvieron obligados -por mandato constitucional-a presentar el mismo número de candidatas y candidatos a todos los cargos legislativos federales y locales. En las tres elecciones federales observadas entre 2009 y 2015, la cuota de género fue modificándose hasta llegar a la paridad. ¿Qué efectos tuvo la paridad de género en las candidaturas en la conformación del Congreso? En 2009, cuando la cuota de género fue de $40 \%$ pero podía tener sendas excepciones, $31 \%$ de las candidaturas de mayoría relativa fueron para mujeres, y estas consiguieron 52 de 300 curules (17\%) uninominales.

En 2012, cuando la cuota de género se mantuvo en $40 \%$ pero ya sin excepciones, las mujeres tuvieron $41 \%$ de las candidaturas y 91 de 300 curules (30\%). Pues bien, en 2015, con $50 \%$ de las candidaturas, las mujeres obtuvieron 117 curules de mayoría relativa (39\%). Se dice fácil, pero se trata de más del doble de triunfos uninominales para mujeres respecto de 2009. Al incorporar el reparto de asientos plurinominales, las diputadas consiguieron 212 escaños en total, 42,4\% de la Cámara, cifra récord comparada con el $38 \%$ de 2012 y el 28\% de 2009 (Gráfico 3).

Gráfico 3. Elecciones para diputados por mayoría relativa, 2009-2015
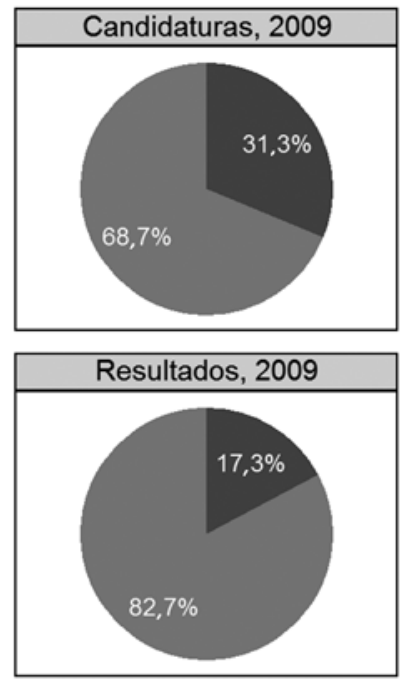
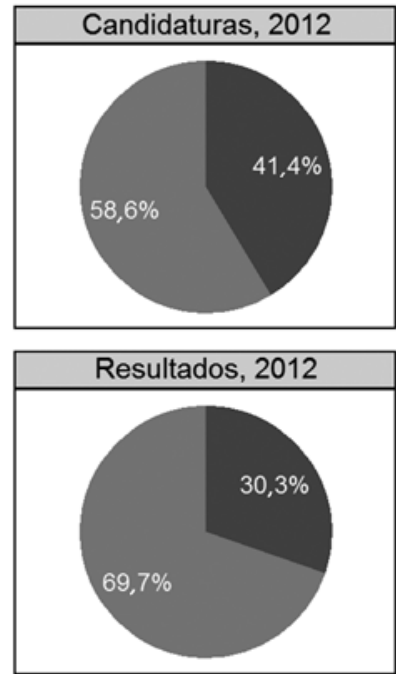
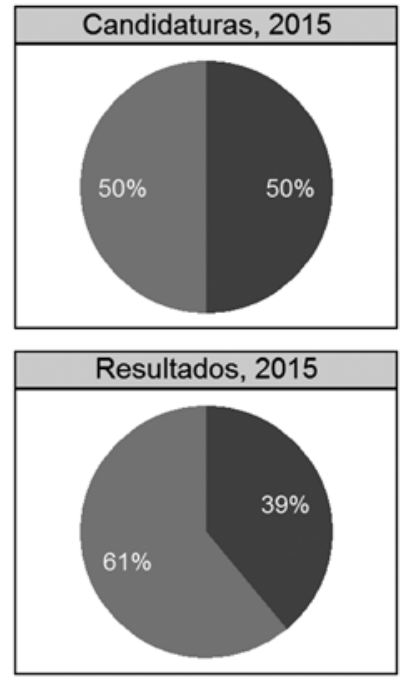

mujeres

\section{hombres}

Fuente: Elaborado a base de cómputos distritales IFE/INE. 


\section{PODER EJECUTIVO}

El único cambio en el gabinete presidencial previo a las elecciones intermedias fue el del Procurador General de la República a los pocos meses de la tragedia de Ayotzinapa. Una vez concluido el proceso electoral federal y previo a rendir su tercer informe de gobierno, el presidente Enrique Peña Nieto anunció diez cambios en su gabinete. Destacan entre los más importantes los siguientes nombramientos: Secretaría de Educación Pública (SEP), Secretaría de Desarrollo Social (SEDESOL), Secretaría de Relaciones Exteriores (SRE) y la Secretaría de Desarrollo Agrario, Territorial y Urbano (SEDATU).

A mitad de su mandato, el presidente Peña Nieto presentó uno de los porcentajes de desaprobación más altos desde que inició su gestión en diciembre de 2012. De noviembre de 2014 a marzo 2016 el Presidente ha registrado un mayor porcentaje de ciudadanos que desaprueban su labor que quienes afirman lo contrario (Buendía y Laredo, 2016).12 De acuerdo con la encuesta realizada en agosto 2015, la desaprobación de Peña Nieto alcanzó un nivel de $57 \%$ frente a $35 \%$ que lo aprobaba. Desde 1995, año de una grave crisis económica, ningún Presidente había mostrado semejantes niveles de desaprobación.

Gráfico 4. En términos generales, ¿usted aprueba o reprueba el trabajo que está haciendo Enrique Peña Nieto como Presidente de la República? ¿Mucho o algo?

Aprueba mucho/algo $\rightleftharpoons$ Ni aprueba ni reprueba $\rightleftharpoons$ Reprueba mucho/algo

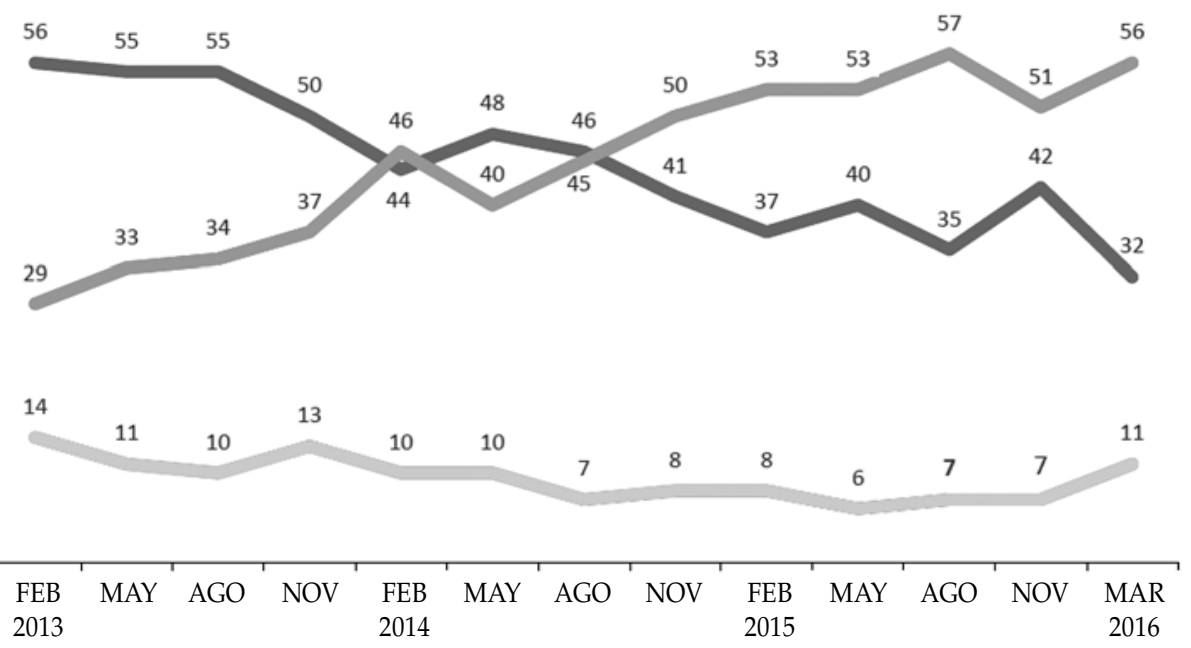

Fuente: Buendía y Laredo. Aprobación Presidencial. Encuesta Nacional Trimestral. Marzo de 2016.

12 Buendía y Laredo (2016). Aprobación Presidencial. Encuesta Nacional Trimestral (marzo). En: http:// buendiaylaredo.com/publicaciones/365/APROBACION_MARZO16.pdf. 
Además de los escándalos de corrupción y la tragedia de Ayotzinapa, las percepciones respecto de la economía y la seguridad pública son dos de los temas que podrían explicar estas tendencias. Según el estudio de Parametría (noviembre 2015), el 71\% de los mexicanos perciben que la situación económica del país había empeorado en los últimos doce meses. Por otro lado, 59\% de los encuestados considera que su colonia era poco o nada segura, $66 \%$ a su municipio y $80 \%$ a su estado. Como se puede ver, la percepción de inseguridad es generalizada (Parametría, 2015). ${ }^{13}$

\section{PODER LEGISLATIVO}

El Gráfico 5 ilustra la composición de la Cámara de Diputados por partido político entre 1994 y 2015. Las bancadas están ordenadas arbitrariamente en el espectro izquierdaderecha y las líneas verticales indican umbrales de 33, 50 y 66 por ciento de la Cámara.

Gráfico 5. Composición de la Cámara de Diputados en México 1997-2018

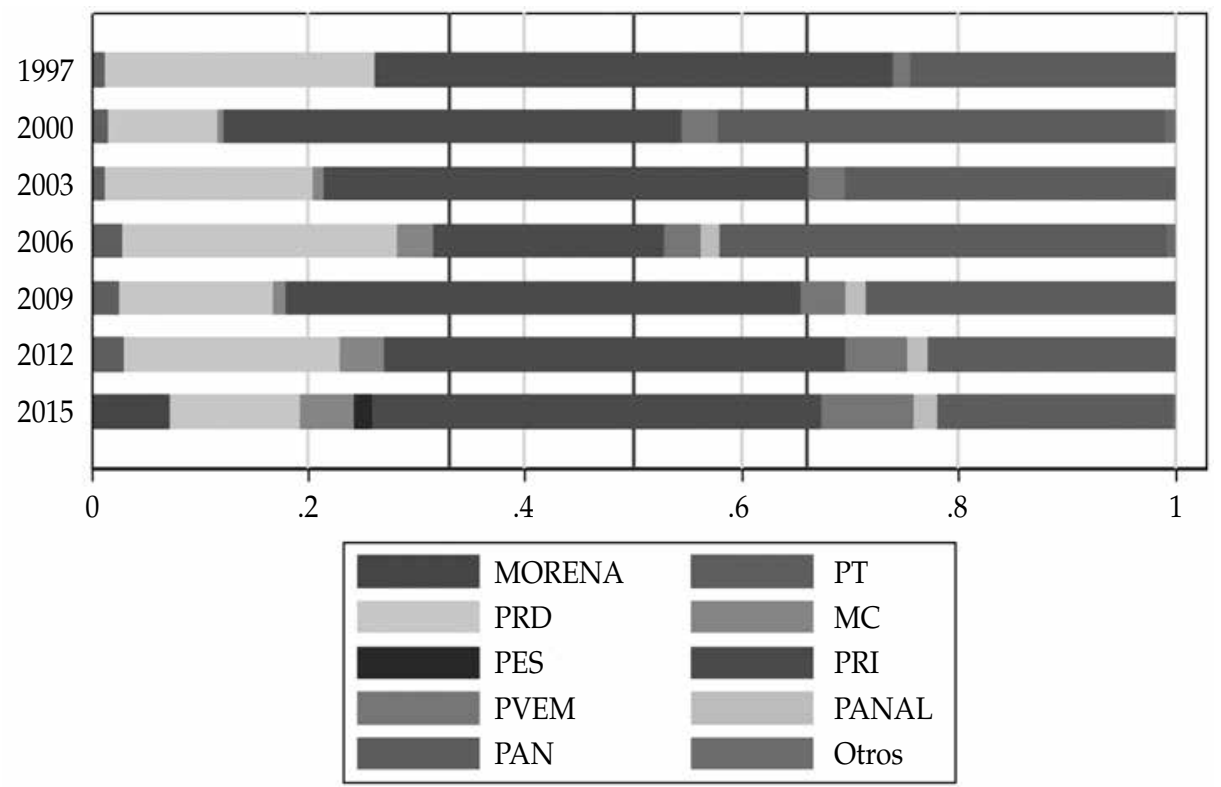

Fuente: Elaborado por Javier Aparicio.

Como se aprecia, la bancada legislativa del PRI en San Lázaro pasó de 60\% en 1994 a 21\% en 2006 pero se recuperó de 2009 en adelante. Por su parte, Vicente Fox inició su mandato en el 2000 con una bancada de 41\%, mismo porcentaje que tuvo Felipe Calderón seis años después. Es decir, que desde 1997 ningún Presidente ha tenido

13 Parametría. (2015). Encuesta Nacional en vivienda (noviembre). En: http://www.parametria.com.mx/ carta_parametrica.php?cp=4823/. 
mayoría en la Cámara de Diputados: tanto el PAN como PRI han requerido hacer coaliciones legislativas.

Pero hay otro aspecto igual de importante: salvo la LX legislatura (2006-2009), el PRI nunca ha tenido menos de un tercio de la Cámara, por lo que en todo este periodo siempre ha tenido poder de veto frente a las reformas constitucionales. Por su parte, el PAN solo ha tenido poder de veto para reformas constitucionales en 2000-2003 y en 20062009: los primeros trienios de Vicente Fox y Felipe Calderón. El PRD nunca ha tenido tal fuerza, ni siquiera en coalición con PT y MC. Algo similar ocurre en el Senado. Salvo entre 2006-2009, el PRI siempre ha tenido más de un tercio de los escaños. Por su parte, el PAN tuvo poder de veto constitucional en el Senado durante los doce años en que tuvo la presidencia pero lo perdieron en las elecciones de 2012 (Gráfico 6).

El LX Congreso (2006-2009) fue el único en que el PRI no tuvo poder de veto en ambas Cámaras. En ese período, una coalición PAN-PRD pudo haber aprobado reformas constitucionales sin contar con el apoyo del PRI. Por desgracia, en aquellos años muchos perredistas tenían prácticamente prohibido negociar con los panistas. En la práctica, esto dio al PRI un poder de negociación mucho mayor al esperado, debido al tamaño de su bancada e incluso convirtiéndose en una especie de partido bisagra.

Por su perfil ideológico (a la izquierda del PAN y a la derecha del PRD) (Freidenberg y Došek, 2012), el PRI nunca ha dejado de ser la bancada mediana en ambas Cámaras del Congreso. En la medida que el PAN y el PRD han tenido intereses legislativos ideológicamente opuestos (Gráfico 7), esto implica que es muy difícil construir una coalición ganadora que excluya al PRI para aprobar una reforma legal en el Congreso.

Gráfico 6. Composición de la Cámara de Senadores 1997-2018

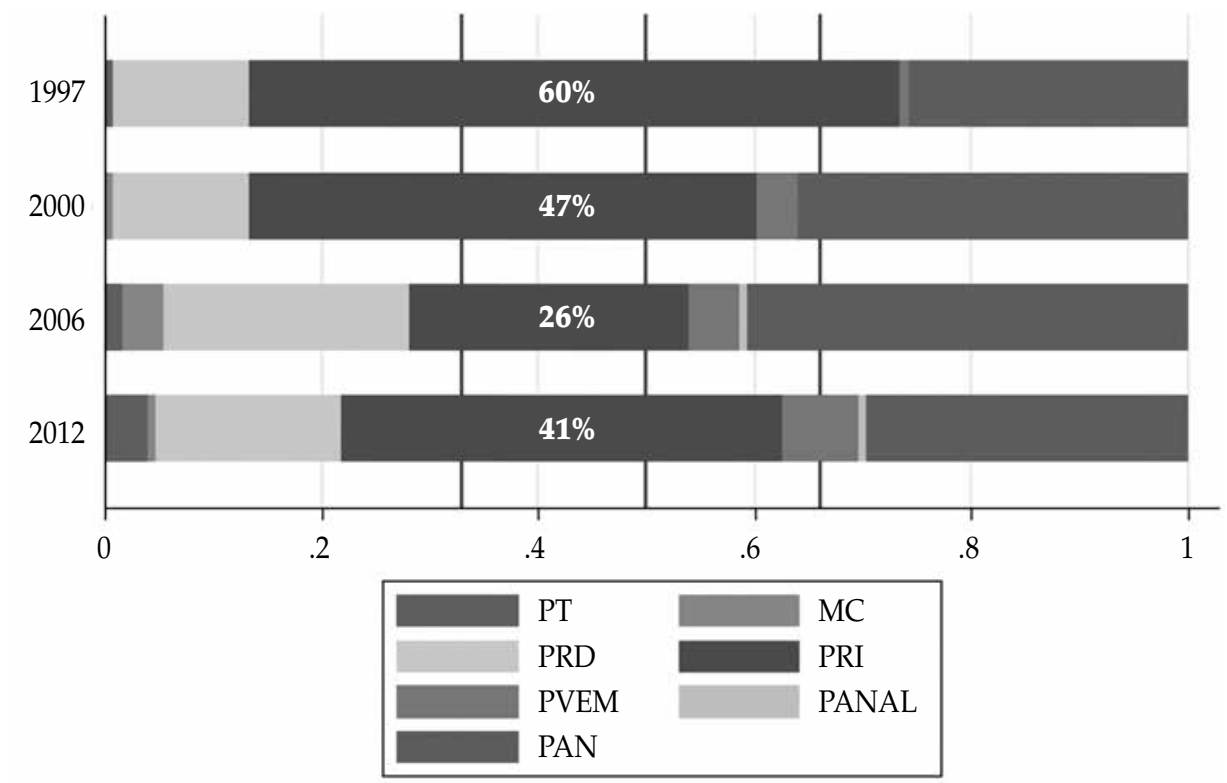

Fuente: Elaborado por Javier Aparicio. 
Tabla 2. Actitudes ideológicas de los legisladores mexicanos

\begin{tabular}{lccccccc}
\hline Legislatura & $1994-1997$ & $1997-2000$ & $2000-2003$ & $2003-2006$ & $2006-2009$ & $2009-2013$ & $\begin{array}{c}\text { Media } \\
\text { período }\end{array}$ \\
\hline Autoubicación media de los diputados & & & & & \\
\hline PAN & 6,15 & 5,29 & 5,88 & 6,44 & 6,20 & 6,47 & 6,07 \\
PRD & 3,65 & 2,77 & 3,08 & 2,82 & 2,25 & 3,57 & 3,02 \\
PRI & 4,94 & 5,90 & 4,71 & 5,22 & 4,46 & 5,02 & 5,04 \\
\hline Identificación media de los partidos & & & & & \\
\hline PAN & 6,45 & 5,42 & 6,38 & 6,94 & 6,67 & 7,41 & 6,55 \\
PRD & 3,27 & 3,00 & 4,18 & 3,14 & 2,44 & 4,77 & 3,47 \\
PRI & 5,4 & 6,00 & 5,25 & 5,61 & 4,96 & 5,28 & 5,42 \\
\hline Posición media de los otros diputados sobre los partidos & & & & \\
\hline PAN & 8,94 & 8,94 & 9,27 & 9,17 & 9,55 & 9,43 & 9,22 \\
PRD & 2,71 & 2,68 & 2,56 & 2,78 & 2,30 & 2,79 & 2,64 \\
PRI & 6,82 & 6,94 & 6,09 & 6,31 & 6,23 & 6,32 & 6,45 \\
\hline
\end{tabular}

Fuente: Freidenberg y Došek (2011), con datos del Proyecto “Élites Parlamentarias en América Latina"-Universidad de Salamanca [PELA].

Gráfico 7. Autoubicación ideológica vs. identificación de los otros

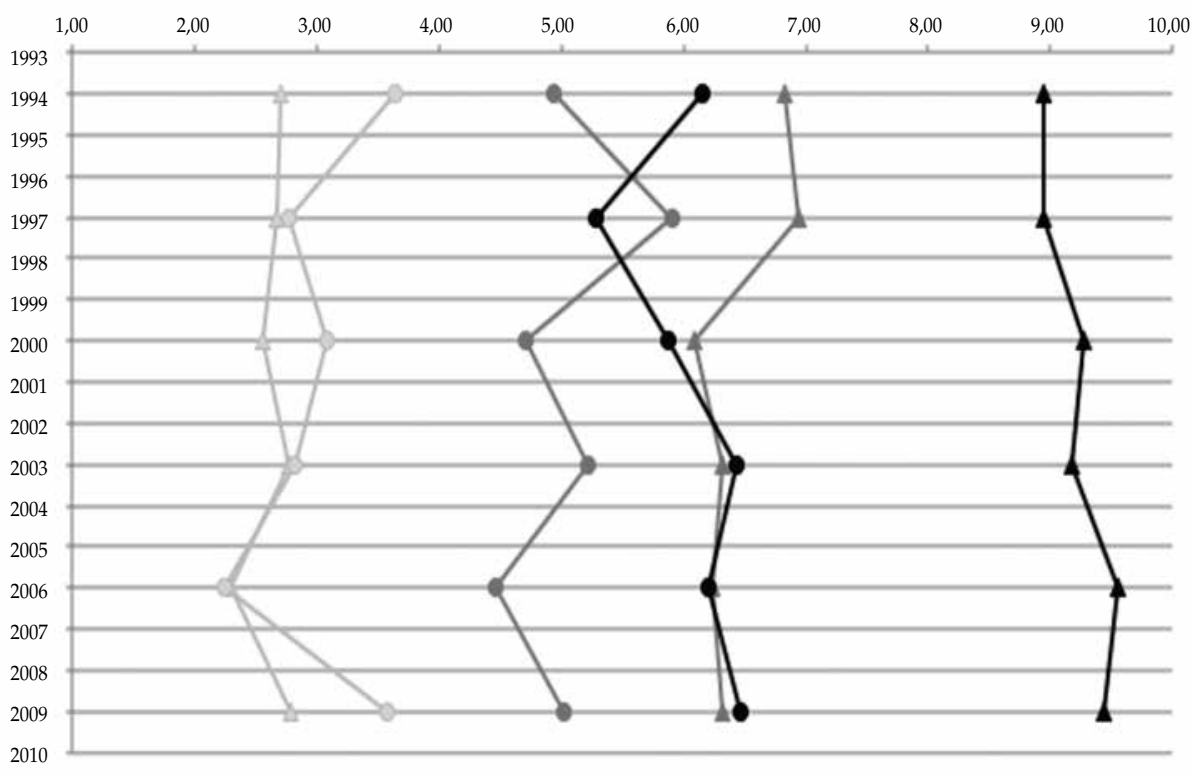

$$
\begin{array}{ll|}
- \text { PRD - Identificación según otros } & - \text { PRI - Identificación según otros } \\
\rightarrow \text { PRD - Autoubicación } & - \text { PAN - Autoubicación } \\
- \text { PRI - Autoubicación } & - \text { PAN - Identificación según otros } \\
\hline
\end{array}
$$

Fuente: Freidenberg y Došek (2012). 
En la LXII Legislatura, vigente entre 2012-2015, ni el PAN ni el PRD tuvieron poder de veto para frenar reformas constitucionales. Por lo demás, una coalición PRI-PRD o bien PRI-PAN resultó suficiente para una reforma legal o constitucional. A causa de la ubicación en el espectro izquierda-derecha de los partidos políticos, el gobierno dividido que enfrentó Enrique Peña Nieto al inicio de su mandato es distinto al que tuvieron Fox y Calderón en su momento. Mientras el PRI siga siendo la bancada mediana del Congreso, un presidente del PRI podrá impulsar su agenda legislativa con mayor facilidad que uno del PAN o PRD.

Por lo general, entre 2012 y 2015 ha sido más fácil para el PRI lograr una coalición ya sea con el PAN o bien con el PRD, o ambos, que para estos crear una coalición opositora. Un claro ejemplo de lo anterior es que durante 2013, tanto la reforma educativa como la de telecomunicaciones y la político-electoral fueron apoyadas por los tres principales partidos. Sin embargo, la reforma energética fue apoyada por el PRI y el PAN, mientras que la reforma fiscal fue apoyada por el PRI y el PRD. Por ello, no resulta sorprendente que el Presidente haya podido impulsar su agenda legislativa con mayor éxito que sus dos antecesores panistas.

Toda vez que en la nueva Legislatura, vigente entre 2015 y 2018, la coalición del PRI mantuvo su mayoría en la Cámara de Diputados, pero sigue estando en minoría en la Cámara de Senadores, es de esperarse que por lo que resta del sexenio las relaciones entre el Ejecutivo y el Legislativo no cambien demasiado. Según se acerque la elección presidencial de 2018 los líderes tanto del PAN como del PRD serán más reacios a negociar con el partido del Presidente, pero es un hecho que el grueso de su agenda legislativa ya fue aprobado entre 2012 y 2015.

\section{EVALUACIÓN DEL FUNCIONAMIENTO Y CALIDAD DE LA DEMOCRACIA}

La democracia requiere un conjunto determinado de valores y prácticas para poder funcionar. Sin esos valores resulta muy difícil contar con un sistema político democrático. Bajos niveles de tolerancia con el que piensa distinto, la desconfianza interpersonal e institucional, la dificultad de respetar y ejercer el pluralismo o la ausencia de una cultura de la legalidad entorpecen el ejercicio de las prácticas democráticas. En México, el compromiso con la democracia como una buena forma de gobierno continúa siendo importante (Moreno y Cebollada, 2013; Olmeda y Armesto, 2013; IFE, 2014), a pesar de que se desconfía de las instituciones y de los políticos y se cree que esa democracia beneficia a pocos (IFE, 2014; Freidenberg y Cisneros, 2016).

Según la investigación del IFE (2014), el mexicano no cree en el Estado de Derecho, ni en la eficiencia del Estado para cumplir con sus tareas. El 66\% no denuncia los delitos y no confía en las autoridades o ha tenido malas experiencias en el pasado que hace que no denuncie esos delitos, lo que supone una cierta cultura de la ilegalidad. Solo tres organizaciones cuentan con la confianza de la mayoría de la población: el Ejército $(62 \%)$, los maestros (56\%) y la Iglesia (55\%). En cuanto a las instituciones políticas y gubernamentales, se confía más en el gobierno federal que en los gobiernos del Estado y 
municipios, mientras que se confía muy poco o casi nada en los partidos y los políticos. Los datos del Latinobarómetro (2015) también ponen en evidencia que los mexicanos, a diferencia de un buen número de países de América Latina, confía poco en las elecciones (Freidenberg y Cisneros, 2016).

Los datos dan cuenta de que existen cimientos precarios para el desarrollo y consolidación de una democracia de alta calidad en México, del mismo modo que se señalaba en la evaluación del 2013 (Barrientos del Monte y Añorve Añorve, 2014) o en la investigación realizada por el IFE (2014). Los niveles de capital social son bajos, existe una gran desconfianza de la ciudadanía a las instituciones, a los actores políticos y a otras personas de su entorno, cree que los políticos no se ocupan de sus demandas y hay un creciente desencanto con los resultados de la democracia (IFE, 2014). Los ciudadanos participan poco en los grupos políticos que facilitan la relación con las instituciones políticas (como los partidos, los sindicatos $\mathrm{u}$ otros) y se asocian poco a nivel sindical o empresarial, aunque participan de manera activa en organizaciones religiosas.

La vida comunitaria es escasa y existen déficits de participación cívica. La ciudadanía rechaza en gran medida la participación no convencional, como las protestas o toma de edificios, como una manera viable de expresar sus demandas. Aun cuando esto varía entre una región y otra, los mexicanos creen que sus acciones no importan ni tienen influencia sobre los procesos políticos, lo que inhibe la acción colectiva. Aún así, las elecciones de 2015 dieron cuenta, una vez más, que en el país los procesos democráticos tienen cada vez mayor legitimidad, a pesar de los niveles de conflictividad política y social que por momentos han puesto en jaque a las autoridades electorales y al sistema político en su conjunto y la crisis cada vez mayor de confianza que tiene la ciudadanía.

Las reformas nacionalizaron la organización de las elecciones y transformaron al IFE en un "súper INE". Los cambios no fueron solo estéticos, también supusieron modificaciones en la manera en que se toman las decisiones dentro del organismo. Los retos de este nuevo modelo de organización de elecciones no han sido pocos. Supone replantear la relación del INE con los organismos y con las élites locales, que en algunos estados de la federación aún hacen política como en tiempos del sistema de partidos hegemónico. También exige que haya más claridad en las competencias y en las fuentes de financiación, la eliminación de funciones superpuestas y aprendizajes conjuntos y mecanismos de cooperación respecto de cómo conseguir elecciones de calidad, con menos erogación de recursos y complejidad administrativa. El principal reto en este sentido supone achicar al elefante. Y eso tampoco es una cuestión menor.

Uno de las grandes déficits de la reforma de 2014, de la campaña electoral y de las propias elecciones de 2015 ha sido que estas no han servido para incrementar la confianza de la ciudadanía en el sistema político, en los actores políticos ni en sus instituciones (Freidenberg y Cisneros, 2016). A diferencia de otros procesos reformistas, la reforma de 2014 fue hecha de lejos y a espaldas del debate público y con bajos niveles de legitimidad, incluso para las élites e instituciones estatales que no entienden las razones de por qué se tuvo que hacer esta reforma generando nuevos problemas, eliminando buenas prácticas (como el caso de la urna electrónica en Jalisco o la capacidad de fiscalización autónoma 
del órgano electoral en el Distrito Federal) y sin resolver del todo los problemas que efectivamente existían.

Otra deficiencia ha sido el modo verticalista de negociar la reforma dentro de los partidos, lo que da cuenta de las dificultades de democratización partidista y los problemas para consolidar una democracia de calidad. La negociación fue entre los dirigentes, sin militantes, sin ciudadanía, sin organizaciones de la sociedad civil y sin (casi) diálogo con la academia. Esta experiencia de imposición de la reforma debe ser atendida. Cuando los comicios sean entendidos como un mero procedimiento técnico para distribuir el poder, y no un encono de conflicto encarnizado, la democracia adquirirá mayores niveles de consolidación. De ahí que varias de las democracias más estables no se preocupen por regular todos los comportamientos, no cuenten con una gran maquinaria electoral ni tampoco gasten mucho dinero en ello.

Las elecciones intermedias realizadas en 2015 alertaron acerca de la existencia de tensiones y debilidades de los procesos políticos, que deberían devenir en aprendizajes tanto para la sociedad mexicana como para la política comparada. De algún modo, muchas de esas tensiones son comunes a otros países y suponen desafíos para los demócratas de la región. Después de varios meses, las autoridades, los partidos e incluso los propios ciudadanos no solo parecen estar exhaustos por la intensa actividad electoral, sino que además deberían reflexionar respecto de los caminos a seguir tras haber enfrentado retos importantes vinculado a la presencia de actores no políticos e incluso paraestatales con capacidad de influencia en los procesos e incluso con problemas para garantizar la seguridad de los competidores y de los ciudadanos.

A más de dos décadas de la llamada transición democrática, el sistema político y el andamiaje electoral en México sigue quedando a debe a las y los ciudadanos. Ni la competitividad electoral ni la alternancia a nivel local o federal parecen haber ofrecido los resultados esperados. Como expresó en una de sus intervenciones el Consejero Presidente del Instituto Nacional Electoral, Lorenzo Córdova Vianello: "Si queremos elecciones sin tantos sobresaltos (elecciones más aburridas), necesitamos tener menos pobres, menos desigualdad y menos impunidad y corrupción" ${ }^{14} \mathrm{El}$ reto por venir trata de contar con un sistema político más incluyente y de fortalecer los mecanismos de control horizontal y vertical de la incipiente democracia mexicana.

\section{REFERENCIAS}

Astudillo Reyes, César. 2016. “La postulación de candidaturas partidistas e independientes en América Latina en el contexto de los derechos de participación política". En Reformas a las organizaciones de partidos en América Latina, editado por Flavia Freidenberg, y Betilde Muñoz-Pogossian. Lima: Pontificia Universidad Católica del Perú, Organización de los Estados Americanos, Instituto de Investigaciones Jurídicas de la UNAM y Sociedad Argentina de Análisis Político, 109-132. 
Barrientos del Monte, Fernando y Añorve Añorve, Daniel. 2014. "México 2013: Acuerdos, reformas y descontento". Revista de Ciencia Política 34 (1): 221-247.

Cantú, Francisco y Ley, Sandra. 2016. "At the Polling Station: The Determinants of Citizen Participation in the Organization of Elections". Working paper. University of Houston y CIDE.

Carreras, Miguel y Trelles, Alejandro. 2012. "Bullets and votes: Violence and electoral participation in Mexico". Journal of Politics in Latin America 4 (2): 89-123.

Freidenberg, Flavia y Došek, Tomas. 2011. “¿Qué divide a los políticos? Actitudes, valores y preferencias de los diputados en México (1994-2013)”. Revista Mexicana de Estudios Electorales 11 (julio): 135-159.

Freidenberg, Flavia y Cisneros, Isaac. 2016. "Confianza”. Revista Voz y Voto 279 (mayo): 40-44.

Instituto Federal Electoral. 2014. Informe sobre la Calidad de la Ciudadanía en México. México: Instituto Federal Electoral y El Colegio de México.

Latinobarómetro 2015. Informe Latinobarómetro 2015. En: http:/ /www.latinobarometro.org/LATDocs/ F00004377-DC_EVE_213_16-INFORME_LB_2015.pdf.

Ley, Sandra. 2014. "Citizens in Fear: Political Participation and Voting Behavior in the Midst of Violence". Ph.D. Dissertation. Duke University.

Moreno, Alejandro y Cebollada, Marta. 2013. Opinión Pública. Representación política y democracia en México. México: ITAM.

Olmeda, Juan C. y Armesto, María A. 2013. "México: el regreso del PRI a la Presidencia". Revista de Ciencia Política 33 (1): 247-267.

Palma, Esperanza. 2010. “México: Entre la violencia y la consolidación del sistema de partidos". Revista de Ciencia Política 30 (2): 379-396.

Trejo, Guillermo y Ley, Sandra. 2015. “Municipios bajo fuego”. Nexos. Febrero. En: http:/ /www.nexos. com.mx/?p=24024.

Flavia Freidenberg es investigadora del Instituto de Investigaciones Jurídicas de la Universidad Nacional Autónoma de México. Profesora del Posgrado de Ciencias Políticas y Sociales de la misma Universidad. Editora Asociada en Política y Relaciones Internacionales de Latin American Research Review. Es Licenciada en Ciencia Política (Universidad de Belgrano, Argentina), Periodista (TEA, Argentina), Máster en Estudios Latinoamericanos y Doctora en Ciencia Política por la Universidad de Salamanca (España). E-mail: flavia@unam.mx.

Francisco Javier Aparicio es profesor-investigador de la División de Estudios Políticos del CIDE. Es Licenciado en Economía por la Universidad de las Américas -Puebla, y cuenta con Maestría y Doctorado en Economía, con especialidad en Economía Política por George Mason University (Estados Unidos). E-mail: javier.aparicio@cide.edu. 